\title{
Diagnosing organizational culture: An empirical investigation
}

\author{
Manouchehr Jofreh $^{\mathrm{a}^{*}}$ and Elahe Sadat Masoumi ${ }^{\mathrm{b}}$
}

${ }^{a}$ Assistant Professor, Department of Management, Central Tehran Branch, Islamic Azad University, Tehran, Iran

${ }^{b}$ Master Student, Department of Management, Central Tehran Branch, Islamic Azad University, Tehran, Iran

\section{H R O N I C L E}

\section{Article history:}

Received May 16, 2013

Received in revised format

28 June 2013

Accepted 10 August 2013

Available online

August 122013

Keywords:

Organizational culture

Denison model

Organizational framework

\section{A B S T R A C T}

Investigating the behavior of members of an organization is a basic step in understanding the organization's culture. In fact, it is always necessary to consider organization culture when a new action is about to happen. In fact, by leveraging culture, it is getting easier to accomplish other tasks within organization. In this paper, we present an empirical investigation to find important factors influencing organizational culture in banking industry. The proposed study uses Denison's standard questionnaire for diagnosing organizational culture. Cronbach alpha has been calculated as 0.927, which is well about the acceptable limit. The results indicate that dimensions of job involvement (2.961) and organizational mission (2.914) are in better position compared with dimensions of compatibility (2.724) and consistency (2.621). The study proposes a new comprehensive organizational framework, which helps building new strategies.

C 2013 Growing Science Ltd. All rights reserved.

\section{Introduction}

Organizational culture plays an important role on the success of business units and there are many evidences, which imply there is a positive correlation between organizational performance and organizational culture (Ashkanasy et al., 2000; Kinicki \& Kreitner, 2006). In fact, many Japanese firms owe their success for having a high level of organizational culture and employee commitment (Mobley et al., 2005). Barbosa and Cabral-Cardoso (2007) looked at the way higher-education firms were responding to the challenges of an increasingly diverse academic force and the extent to which organizational culture welcomed and values diversity, thus permitting the university to take advantage from talented people with diverse backgrounds. They reported that the firm studied was failing to promote equal opportunities policies and to manage the increasingly diverse academic workforce.

\footnotetext{
*Corresponding author

E-mail address: dr.jofreh@yahoo.com (M. Jofreh) 
Henri (2006) examined the relationships between organizational culture and the diversity of measurement and the nature of use. They reported that top managers of firms reflecting a flexibility dominant type tend to implement more performance measures and to implement PMS to concentrate organizational attention, support strategic decision-making and legitimate actions to a bigger extent than top managers of firms reflecting a control dominant kind. Kwantes and Boglarsky (2007) examined perceptions of which aspects of organizational culture are associated with leadership and personal effectiveness using archival data from Canada, Hong Kong, New Zealand, South Africa, the United Kingdom, and the United States. They reported that organizational culture was strongly associated with both leadership effectiveness and personal effectiveness.

Philip and McKeown (2004) examined the contribution which anthropology could make in the study of organizational culture and more specifically, in testing the relationship between culture and business transformation. They reported that the cultural changes had been brought about through a range of strategies such as the development of managerial and organizational competencies, information systems, and quality management practices. Tsui et al. (2006) gave an insight on when and why decoupling between CEO leadership behavior and organizational culture may happen. They investigated this issue in a novel context, the People's Republic of China, where there was large variance on leader discretion in various kinds of firms. They built two survey investigations and an interview study to unpack the nature of the relationship. The findings offered some insights on both leadership and institutional factors, which could account for the decoupling between CEO leadership behavior and organizational cultural values. They also offered directions for future research on both leadership and organizational culture phenomena and their potential relationships. Yilmaz and Ergun (2008) investigated organizational culture and firm effectiveness by examining relative effects of culture traits and the balanced culture hypothesis in an emerging economy.

\section{The proposed study}

Denison model has been a popular model for learning more about organizational culture. Fig. 1 demonstrates details of Denison dimensions. The questionnaire consists of 60 questions in Likert scale and Cronbach alpha has been calculated as 0.927 , which is well about the acceptable limit.

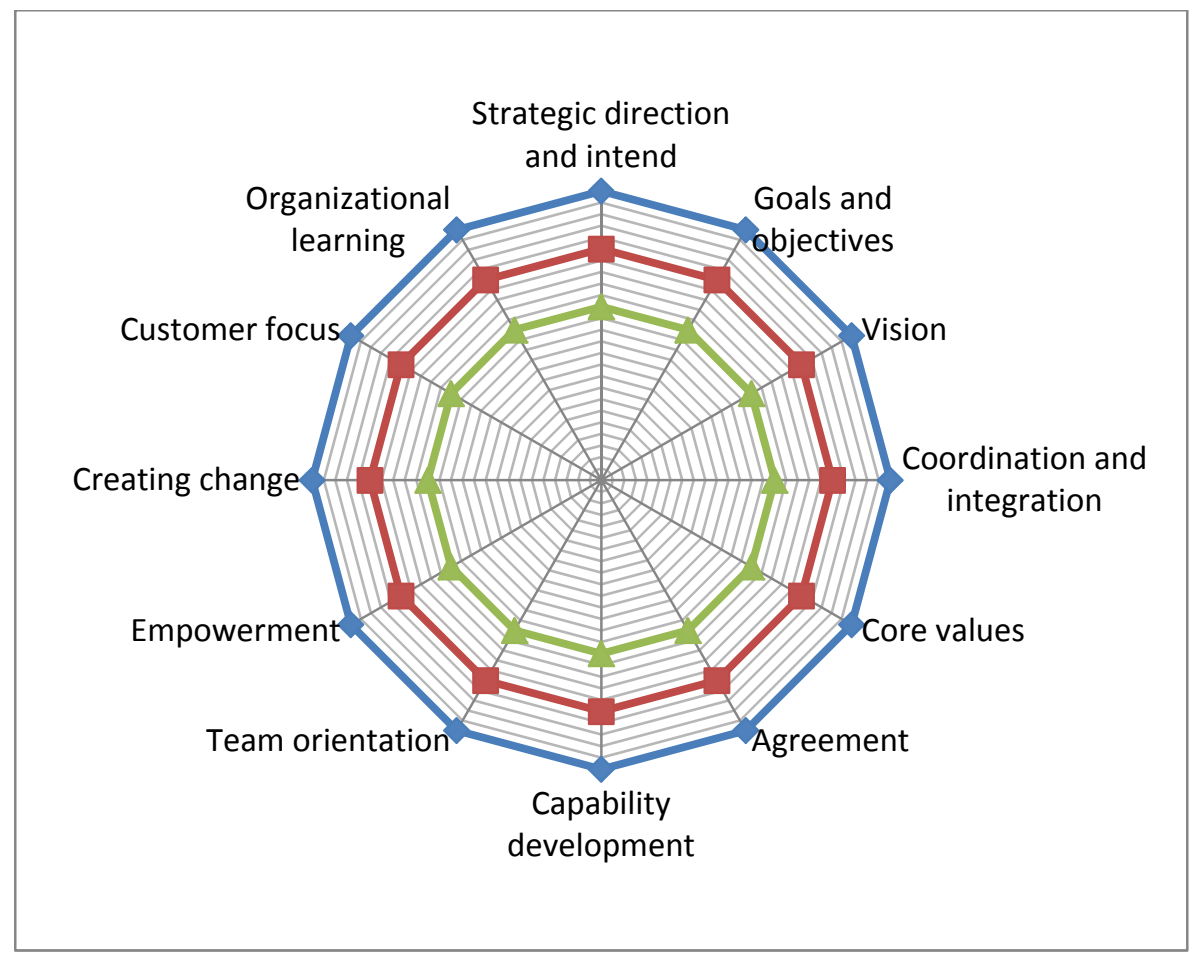

Fig. 1. The structure of Denison model 
The proposed study of this paper uses Denison's standard questionnaire to examine the following six questions,

1. What is the status of organizational culture in terms of job involvement?

2. What is the status of organizational culture in terms of consistency?

3. What is the status of organizational culture in terms of compatibility?

4. What is the status of organizational culture in terms of mission?

5. What sort of changes does organizational culture need in macro scale?

6. What is the relationship between the main dimensions and Denison model.

The study is accomplished in some of administration offices in Bank Melli Iran located in city of Tehran, Iran. The sample size is calculated as follows,

$n=\frac{N \times z_{\alpha / 2}^{2} \times p \times q}{\varepsilon^{2} \times(N-1)+z_{\alpha / 2}^{2} \times p \times q}$,

where $N$ is the population size, $p=1-q$ represents the yes/no categories, $z_{\alpha / 2}$ is CDF of normal distribution and finally $\varepsilon$ is the error term. Since we have $p=0.5, z_{\alpha / 2}=1.96$ and $N=2555$, the number of sample size is calculated as $n=93$. We have decided to distribute 100 questionnaires among the employees who participated in this survey.

\section{The results}

After gathering the necessary data, we first look at the mean of scores given in four criteria used for the proposed study of this paper and it seems that the average scores given to job involvement (2.961) and organizational mission (2.914) are in better position compared with dimensions of compatibility (2.724) and consistency (2.621). Fig. 2 demonstrates the summary of preliminary findings,

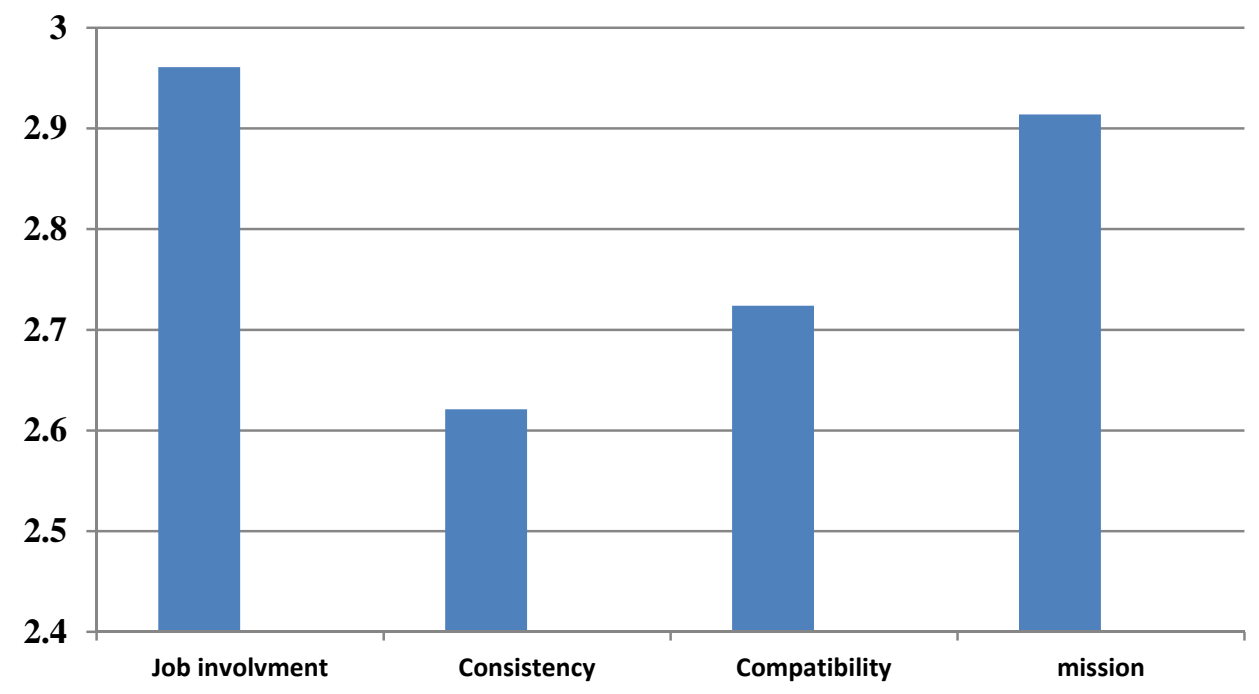

Fig. 2. The results of scores for the main components of the questionnaire 
In addition, we have measured the scores assigned to job involvement, consistency, compatibility and mission for different groups of employees, experts, staff and officers, and Fig. 3 demonstrates the results of our survey.

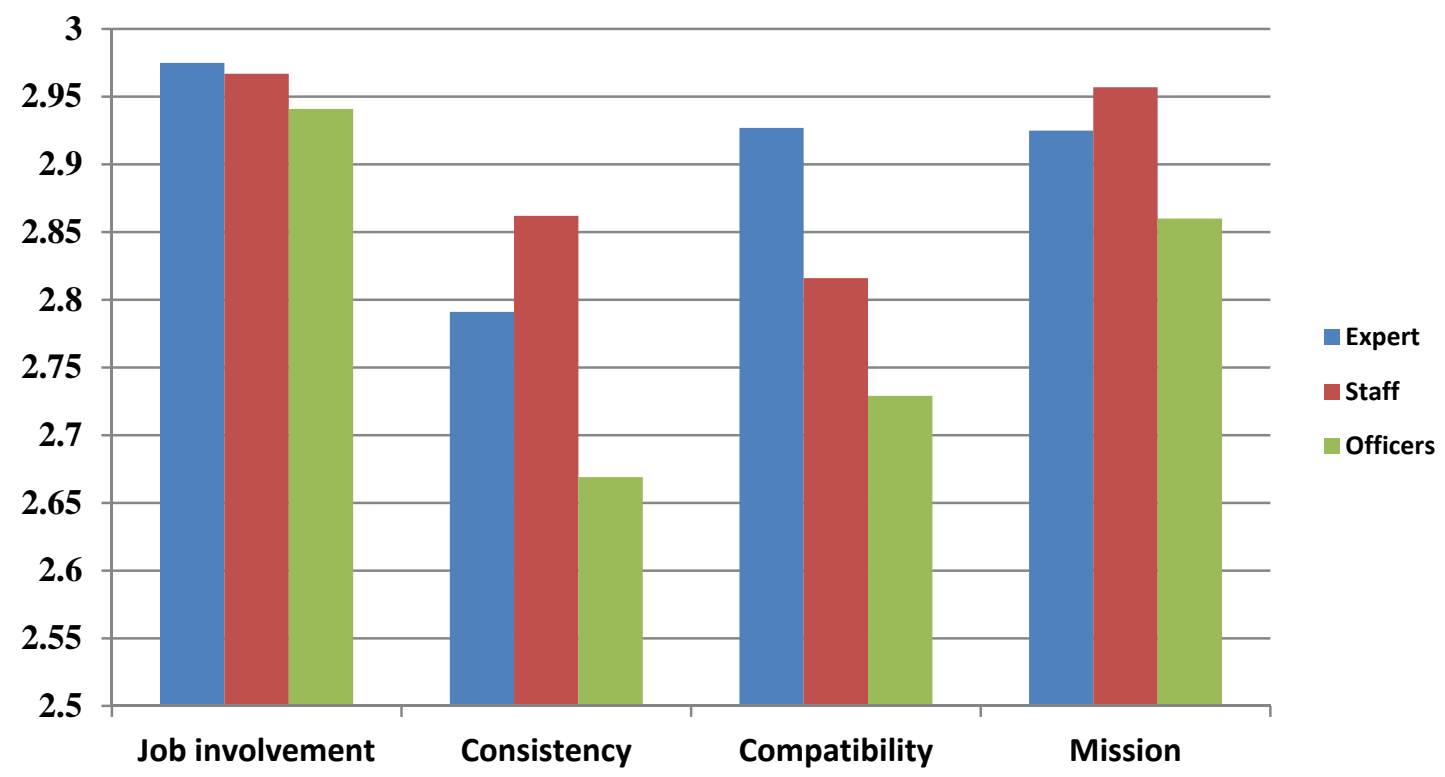

Fig. 3. The mean scores given to experts, staff and officers

Next, we have measured the mean score given to each component of the questionnaire and Fig. 4 demonstrates the results of our survey. Table 1 presents details of the scores.

Table 1

The summary of scores given to each item

\begin{tabular}{clccc}
\hline \multirow{2}{*}{ Main components } & \multicolumn{1}{c}{ Attributes } & Mean score & \\
& & Experts & Staff & Employee \\
\hline \multirow{3}{*}{ Job involvement } & Strategic direction and intend & 2.982 & 2.974 & 2.947 \\
& Goals and objectives & 2.956 & 2.944 & 2.92 \\
& Vision & 2.987 & 2.983 & 2.956 \\
\hline \multirow{3}{*}{ Consistency } & Coordination and integration & 2.707 & 2.894 & 2.584 \\
& Core values & 2.847 & 2.871 & 2.596 \\
& Agreement & 2.819 & 2.821 & 2.827 \\
\hline \multirow{3}{*}{ Compatibility } & Capability development & 2.934 & 2.774 & 2.673 \\
& Team orientation & 2.872 & 2.825 & 2.772 \\
& Empowerment & 2.975 & 2.849 & 2.742 \\
\hline \multirow{2}{*}{ Mission } & Creating change & 2.894 & 2.945 & 2.857 \\
& Customer focus & 2.937 & 2.959 & 2.874 \\
& Organizational learning & 2.944 & 2.967 & 2.849 \\
\hline
\end{tabular}

According to the results of Table 1, job involvement includes three attributes of strategic direction and intends, goals and objectives and vision and they are all within acceptable limits. Consistency is the second component of the survey, which is associated with three sub-components including coordination and integration, core values and agreement. The scores given to these components are also within acceptable limits. The third item, compatibility, also consists of three sub-components including capability development, team orientation and empowerment and they are within acceptable limits. Finally, the last item, mission, includes three attributes including creating change, customer focus and organizational learning and they are within desirable level. 


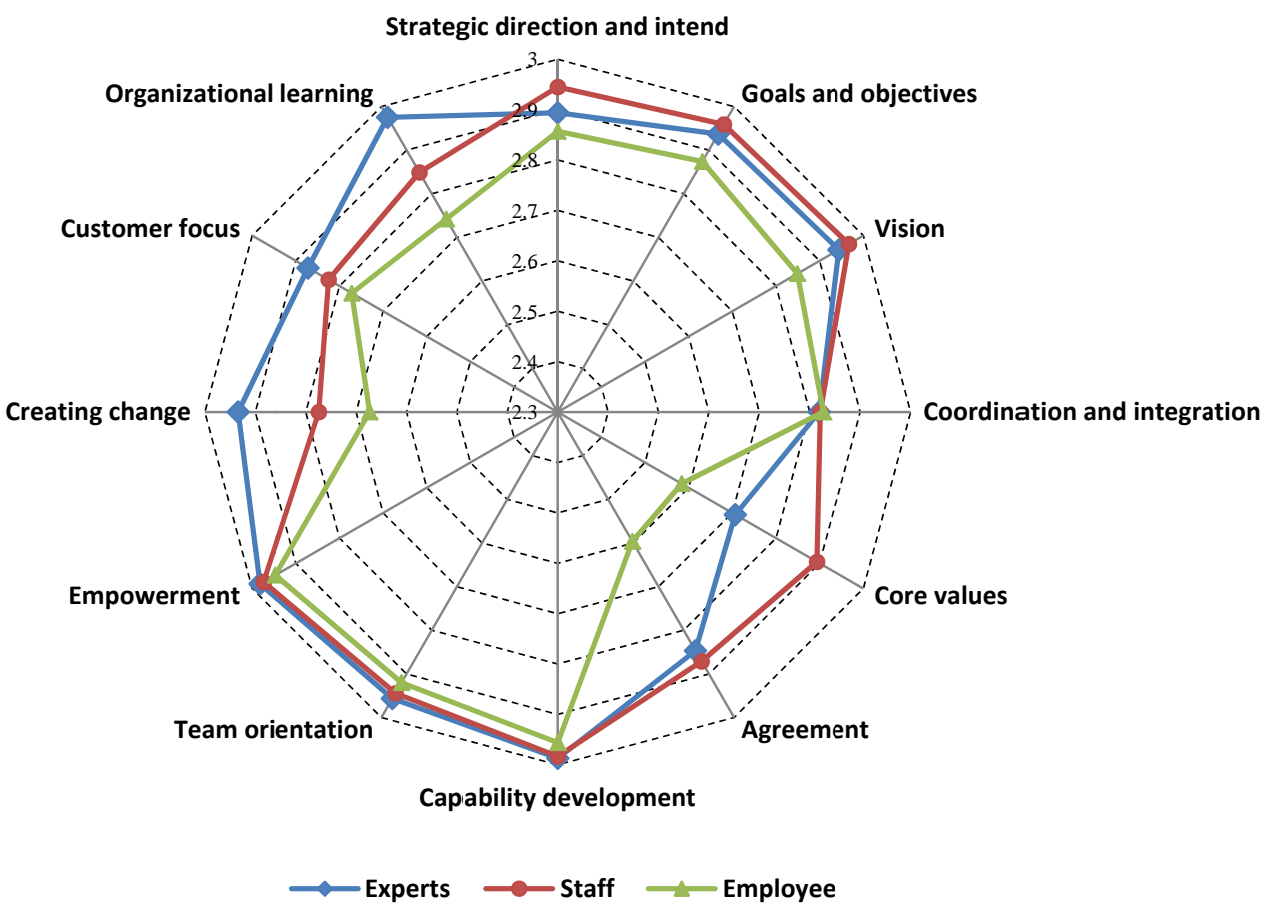

Fig. 4. The summary of scores given to each item in survey

As we can observe from the results of Fig 4, there seems to be a good correlation among different components of the questionnaire. To verify this, we apply Pearson correlation test among different components and Table 2 summarizes the results of our survey.

\section{Table 2}

The summary of Pearson correlation test

\begin{tabular}{lcccc}
\hline Dimension & Job involvement & Mission & Compatibility & Consistency \\
\hline Job involvement & 1.000 & 0.675 & 0.627 & 0.524 \\
Consistency & 0.524 & 0.612 & 0.605 & 1.000 \\
Compatibility & 0.627 & 0.654 & 1.000 & 0.605 \\
Mission & 0.675 & 1.000 & 0.654 & 0.612 \\
\hline
\end{tabular}

The results of Table 2 clearly specify that there are some strong and positive correlations among four main components of this survey. The highest correlation ratio is between mission and job involvement (0.675). The correlation ratio between compatibility and mission is equal to 0.654 , which is the second largest correlation. The results indicate that there is a good consistency among different components of organizational culture for the case study of the proposed model.

\section{Conclusion}

In this paper, we have presented an empirical investigation to find important factors influencing organizational culture in banking industry. The proposed study has adapted a questionnaire based on Denison organizational culture dimensions and distributed it among different groups of employees who worked for one of Iranian banks in city of Tehran, Iran. The results of our survey has concluded that while dimensions of job involvement (2.961) and organizational mission (2.914) were in better position compared with dimensions of compatibility (2.724) and consistency (2.621), there were some positive and meaningful correlation among all four components. 


\section{Acknowledgment}

The authors would like to thank the anonymous referees for constructive comments on earlier version of this paper.

\section{References}

Ashkanasy, N. M., Wilderom, C. P., \& Peterson, M. F. (Eds.). (2000).Handbook of organizational culture and climate. Sage.

Barbosa, Í., \& Cabral-Cardoso, C. (2007). Managing diversity in academic organizations: a challenge to organizational culture. Women in Management Review, 22(4), 274-288.

Denison, D. R., Janovics, J., Young, J., \& Cho, H. J. (2006). Diagnosing organizational cultures: Validating a model and method. Documento de trabajo. Denison Consulting Group.

Henri, J. F. (2006). Organizational culture and performance measurement systems. Accounting, organizations and society, 31(1), 77-103.

Kinicki, A., \& Kreitner, R. (2006). Organizational behavior: Key concepts, skills \& best practices. McGraw-Hill/Irwin.

Kwantes, C. T., \& Boglarsky, C. A. (2007). Perceptions of organizational culture, leadership effectiveness and personal effectiveness across six countries. Journal of International Management, 13(2), 204-230.

Mobley, W. H., Wang, L., \& Fang, K. (2005). Organizational culture: measuring and developing it in your organization. Harvard Business Review China, 3, 128-139.

Philip, G., \& McKeown, I. (2004). Business transformation and organizational culture:: The role of competency, IS and TQM. European Management Journal, 22(6), 624-636.

Tsui, A. S., Zhang, Z. X., Wang, H., Xin, K. R., \& Wu, J. B. (2006). Unpacking the relationship between CEO leadership behavior and organizational culture. The Leadership Quarterly, 17(2), 113-137.

Yilmaz, C., \& Ergun, E. (2008). Organizational culture and firm effectiveness: An examination of relative effects of culture traits and the balanced culture hypothesis in an emerging economy. Journal of World Business, 43(3), 290-306. 